Original Research

\title{
Single-Leg Vertical Hop Test Detects Greater Limb Asymmetries Than Horizontal Hop Tests After Anterior Cruciate Ligament Reconstruction in NCAA Division 1 Collegiate Athletes
}

\author{
Michael J Zarro, $\mathrm{PT}^{1}$, , Matthew G Stitzlein, BS ${ }^{2}$, Jason S Lee, BS ${ }^{2}$, Robert W Rowland, PT', Vicki L Gray, PT, PhD², Jeffrey \\ B Taylor, PT, $\mathrm{PhD}^{3}$, Sean J Meredith, MD ${ }^{4}$, Jonathan D Packer, $\mathrm{MD}^{4}$, Christa M Nelson, PT, PhD ${ }^{5}$ \\ 1 Department of Physical Therapy and Rehabilitation Science, University of Maryland School of Medicine; Department of Orthopaedics, University of \\ Maryland School of Medicine, ${ }^{2}$ Department of Physical Therapy and Rehabilitation Science, University of Maryland School of Medicine, ${ }^{3}$ Department \\ of Physical Therapy, High Point University, ${ }^{4}$ Department of Orthopaedics, University of Maryland School of Medicine, ${ }^{5}$ Department of Physical \\ Therapy and Human Movement Sciences, Northwestern University Feinberg School of Medicine \\ Keywords: hop testing, return to sport, rehabilitation, acl reconstruction, anterior cruciate ligament, movement system \\ https://doi.org/10.26603/001c.29595
}

\section{International Journal of Sports Physical Therapy}

Vol. 16, Issue 6, 2021

\section{Background}

Knee function deficits may persist after anterior cruciate ligament reconstruction (ACLR). Return to sport (RTS) testing batteries assess recovery after ACLR and can guide RTS progression, but the ideal test components are debatable. The single leg vertical hop for height (SLVH) test using a commercially available jump mat may provide a valuable assessment of knee function.

\section{Hypothesis/Purpose}

The purpose of this study was to compare the limb symmetry index (LSI) of SLVH to horizontal hop testing in a cohort of National Collegiate Athletic Association (NCAA) Division 1 collegiate athletes after ACLR. The hypothesis was the SLVH would elicit significantly lower LSI than horizontal hop tests.

\section{Study design}

Cross-Sectional Study

\section{Methods}

Eighteen National Collegiate Athletic Association (NCAA) Division 1 collegiate athletes (7 males, 11 females) at $7.33 \pm 2.05$ months after ACLR were included in this retrospective study. LSI was calculated for single hop for distance (SHD), triple hop for distance (THD), cross-over hop for distance (CHD), timed 6-meter hop (T6H), and SLVH. A repeated measures ANOVA was performed to identify differences in LSI for each test. Spearman's Rho correlation coefficient was calculated to examine the relationship between LSIs for each test.

\section{Results}

The LSI for SLVH $(84.48 \% \pm 11.41 \%)$ was significantly lower than LSI for SHD $(95.48 \pm$ $8.02 \%, \mathrm{p}=0.003)$, THD $(94.40 \pm 3.70 \%, \mathrm{p}=0.002)$, CHD $(95.85 \pm 7.00, \mathrm{p}=0.007)$, and T6H $(97.69 \pm 6.60 \%, p=0.001)$. The correlation of LSI between SLVH and the horizontal hop tests was weak and non-significant for SHD ( $\left.\mathrm{r}_{\mathrm{s}}=0.166, \mathrm{p}=0.509\right)$, CHD $\left(\mathrm{r}_{\mathrm{s}}=0.199, \mathrm{p}=\right.$ $0.428)$, and $\mathrm{T} 6 \mathrm{H}\left(\mathrm{r}_{\mathrm{s}}=0.211, \mathrm{p}=0.401\right)$ and moderate and non-significant for THD $\left(\mathrm{r}_{\mathrm{s}}=\right.$ 
$0.405, \mathrm{p}=0.096)$.

\section{Conclusions}

Individuals after ACLR had lower LSI on the SLVH than on horizontal hop tests and weak to moderate correlations between the tests suggest SLVH detects performance deficits not identified by the horizontal hop tests.

\section{Level of evidence}

3

\section{INTRODUCTION}

Over 120,000 anterior cruciate ligament (ACL) tears per year occur in the United States. ${ }^{1}$ In athletes, the majority of these tears are addressed with ACL reconstruction (ACLR) surgery. ${ }^{2}$ Post-operatively, rehabilitation is crucial to restore function and promote a safe return to activities of daily living and sport. Despite current rehabilitation standards and return to sport criteria, outcomes still may not be optimal. A systematic review of prospective studies that followed patients for at least five years post-surgery reported in the pooled data that $5.8 \%$ of ipsilateral ACLR autografts failed and $11.8 \%$ of patients had an ACL tear in the contralateral limb. ${ }^{3}$ Ardern et al. reported pooled return to sport rates of $74 \%$ to $87 \%$, however, only $59 \%$ to $72 \%$ of patients returned to their preinjury sport, and only $46 \%$ to $63 \%$ returned to competitive sports. ${ }^{4}$ Level of play is an important variable to consider after ACLR as it may help discern whether athletes are not doing as well as originally thought. 5,6

Return to sport (RTS) testing batteries are used by sports medicine and rehabilitation professionals to measure outcomes and provide guidelines for clinical decision making during the RTS progression. ${ }^{7-12}$ They may be a helpful component of the return to sport process and ultimately improve outcomes by identifying athletes in need of continued rehabilitation. Traditional horizontal hop testing that measures the distance one can hop forward is a commonly used component of these batteries. ${ }^{7,13}$ These tests include a number of hopping tasks that assess either the distance one can hop in single or multiple unilateral jumps, or the time it takes an individual to hop on the impaired limb a specified distance. However, all of these tasks assess hopping in a primarily forward direction. In contrast, the single leg vertical hop for height (SLVH) test measures the height that one can hop upward and is emerging as a useful assessment of knee function after ACLR. ${ }^{14-17}$ This is because the SLVH test relies more heavily on the power generated by the quadriceps to create a vertical impulse than the traditional horizontal hop tests. ${ }^{15,18}$ Achieving $\geqslant 90 \%$ limb symmetry index (LSI), a value comparing the performance on the involved to the uninvolved limb, is often advocated as a marker of successful rehabilitation. ${ }^{10,11,19}$ A benefit of hop testing is that it is easy to perform in the clinic and has demonstrated appropriate reliability and validity to use after ACLR. ${ }^{20}$ Other common tests/measures include measurements of strength, power, graft integrity, movement quality, psychological readiness, and patient reported outcomes. ${ }^{5,9,15,21-27}$ However, controversy exists over the ideal combination of tests to use, if results on these tests are associated with better outcomes, and how these tests assess knee function. ${ }^{23,28-34}$ This conflicting information poses challenges to sports medicine and rehabilitation professionals when considering how to objectively guide RTS decision making. ${ }^{35}$

Further exploration of RTS testing options will allow clinicians to better select outcome measures that assess relevant components of knee function. ${ }^{36,37}$ The SLVH test is easy to administer and may provide helpful information regarding knee function after ACLR. ${ }^{14,15,33}$ Taylor et al. found greater LSI asymmetries on the SLVH compared to horizontal hop tests and poor correlation between SLVH and the horizontal hop tests, suggesting that SLVH may measure constructs that horizontal tests cannot. ${ }^{16}$ While promising, that study had wide inclusion criteria that analyzed individuals many years $(4.7 \pm 2.6)$ after surgery and used 3D motion capture and force plate assessment, which may not be applicable to traditional rehabilitation settings. Exploration of SLVH performance earlier after ACLR through the lens of clinical practice and may help guide clinical decision making during the later stages of rehabilitation. The purpose of this study was to compare the LSI of SLVH to horizontal hop testing in a cohort of National Collegiate Athletic Association (NCAA) Division 1 collegiate athletes after ACLR. It was hypothesized that the SLVH would elicit significantly lower LSI than the horizontal hopping tests and provide unique information from the horizontal hopping tests to be used in clinical decision making after ACLR.

\section{METHODS}

\section{PARTICIPANTS}

A retrospective review was conducted to examine a consecutive series of patients between August 2018- November 2020 who met the inclusion criteria of NCAA Division 1 collegiate athletes referred to the University of Maryland Sports Medicine practice to assess their recovery after unilateral ACLR. Patients were excluded from the study for 1) a history of prior ACLR to either knee or 2) any other lower extremity musculoskeletal surgery within the previous two years. To determine sample size, an a priori power analysis was conducted based on the work of Taylor et al. ${ }^{16}$ A sample size of 14 was required to detect an effect size of 0.8 for the primary outcome measure, limb symmetry index (LSI), with $\alpha=0.05$ and a power $(1-\beta)=0.80$. The Institutional Review Board at the University of Maryland, Baltimore determined this study to be exempt.

\section{PROCEDURES}

The necessary demographic and hop testing data were ex- 
tracted and de-identified from subjects' electronic medical records. Demographic data is included in Table 1. Hop testing data collected included limb symmetry indices (LSIs) for a battery of single leg hop tests including: single hop for distance (SHD), triple hop for distance (THD), cross-over hop for distance (CHD), timed 6-meter hop (T6H), and single leg vertical hop for height (SLVH). Data were collected as part of usual clinical practice by physical therapists (authors MZ or RR) who are board-certified in either sports or orthopedic physical therapy and each have over eight years of experience working with patients with ACL injuries.

Testing procedures were based upon previously published instructions and included a warmup, two practice trials, and two test trials; the two test trials were averaged for the final result for each test which was used for statistical analysis. ${ }^{7,8,14}$ Horizontal hop tests (SHD, THD, and CHD) were performed over ground and measured with a tape measure. The $\mathrm{T} 6 \mathrm{H}$ was performed over ground and measured with a standard timer on a smart phone device. The SLVH was performed on the Just Jump System (JJS, Probotics Inc, Huntsville, AL, USA), which is a commercially available jump mat that calculates jump height from flight time between foot contacts and is valid when compared to three-dimensional camera motion capture. ${ }^{38}$

For the SHD, the instructions were to hop as far forward as possible and hold the landing on the testing leg for two seconds. For the THD and CHD, participants were instructed to perform three continuous forward hops and hold the final landing on the testing leg for two seconds. For the $\mathrm{T} 6 \mathrm{H}$, the instructions were to hop on the testing leg as fast as possible down a 6-meter course, with the time needed to complete the course recorded for analysis. For the SLVH (Figure 1), the instructions were to perform a countermovement, single leg vertical hop as high as possible and hold the landing on the testing leg for two seconds. The patients were also instructed not to excessively flex their hips while in the air to prevent artificially increasing flight time but were allowed to use their arms. Limb symmetry indices (LSIs) were calculated by dividing the result on the involved limb by the result on the uninvolved limb and multiplying by 100 to produce a percentage. For the T6H, the numerator and denominator were reversed in the calculation, as a lower time indicates better performance. Therefore, for all tests, a value less than $100 \%$ indicates a worse performance on the surgical limb compared to the non-surgical.

\section{STATISTICAL ANALYSIS}

Descriptive statistics (means and standard deviations) were calculated for all dependent variables. Shapiro-Wilk test was used to assess the normality of the LSI data for each hop test. Repeated measures ANOVAs (within-subject factor: test) were performed to identify differences in LSI across the tests. Post-hoc analysis was conducted when significant main effects were found to evaluate pairwise comparisons for LSI between specific tests. As the Shapiro-Wilk test determined that the LSI for two of the five tests was not normally distributed, non-parametric Spearman's Rho correlation coefficient was used to examine the relationship between limb symmetry index for each test. Additionally, this test has been reported to be more robust to outliers
Table 1. Patient demographics

\begin{tabular}{|c|c|}
\hline Demographic variable & All $(\mathbf{n}=18)$ \\
\hline Male: Number (\%) & $7(39 \%)$ \\
\hline Female: Number (\%) & $11(61 \%)$ \\
\hline Age, years & $20.39 \pm 1.11$ \\
\hline Height, meters & $1.75 \pm 0.09$ \\
\hline Weight, kilograms & $75.61 \pm 15.38$ \\
\hline Body mass index, kilograms/meters ${ }^{2}$ & $24.5 \pm 0.40$ \\
\hline Time since surgery, months & $7.33 \pm 2.05$ \\
\hline
\end{tabular}

Nominal data are displayed as number (\%), interval and ratio data are displayed as mean \pm standard deviation

than the traditional Pearson correlation coefficient. ${ }^{39}$ All statistical analyses were performed using SPSS version 27 (IBM Corp.) with $\mathrm{p} \leqslant 0.05$ indicating statistically significant differences.

\section{RESULTS}

A total of 18 patients ( 7 males, 11 females) with an average age of $20.39 \pm 1.11$ years were included (Table 1$)$. Sports played by patients are presented in Table 2. Data was not analyzed by sport, but this information helps characterize the sample. All patients had undergone primary ACLR with bone-patellar tendon-bone autograft and were an average of $7.33 \pm 2.05$ months since surgery.

There was a difference in LSI across the hop tests, with a significant main effect of hop test on the LSI $(F(4,14)=5.549$, $\mathrm{p}=0.007$ ) seen across the participants (Figure 2). Post-hoc pairwise comparisons show that the LSI for SLVH $(84.48 \% \pm$ $11.41 \%)$ was significantly lower than the LSI calculated for each of the horizontal hop tests: SHD $(95.48 \pm 8.02 \%, \mathrm{p}=$ 0.003), THD ( $94.40 \pm 3.70 \%, \mathrm{p}=0.002)$, CHD (95.85 $\pm 7.00, \mathrm{p}$ $=0.007)$, and $\mathrm{T} 6 \mathrm{H}(97.69 \pm 6.60 \%, \mathrm{p}=0.001)$.

Fourteen patients $(77.78 \%)$ scored $\geqslant 90 \%$ on all four horizontal hop tests. In contrast, only six patients (33.33\%) scored $\geqslant 90 \%$ on the SLVH. Of the fourteen patients who scored $\geqslant 90 \%$ on all four horizontal hop tests, only five patients $(35.71 \%)$ scored $\geqslant 90 \%$ on the SLVH. None of the five patients who scored $\leqslant 90 \%$ on the horizontal hop tests scored $\geqslant 90 \%$ on the SLVH.

There were no statistically significant correlations observed between the LSI for the SLVH to the other four tests (Figure 3). Overall, there were weak correlations between the limb symmetry indices for the SLVH to the SHD $\left(\mathrm{r}_{\mathrm{s}}=\right.$ $0.166, \mathrm{p}=0.509)$, CHD $\left(\mathrm{r}_{\mathrm{s}}=0.199, \mathrm{p}=0.428\right)$, and T6H $\left(\mathrm{r}_{\mathrm{s}}=\right.$ $0.211, \mathrm{p}=0.401)$ and a moderate correlation when comparing the SLVH to the THD $\left(r_{s}=0.405, p=0.096\right)$.

\section{DISCUSSION}

The aim of this study was to compare LSI calculated from the SLVH to four horizontal hop tests after ACLR. The main findings supported the hypothesis that LSI of the SLVH test would be significantly lower than all horizontal hop tests. 


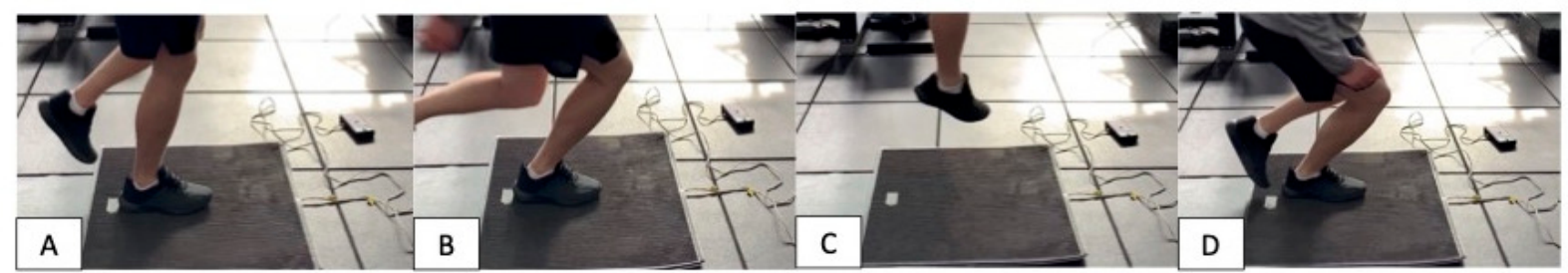

Figure 1. Single Limb Vertical Hop for height, using the Just Jump System.

A. Starting position, B. End of eccentric phase, C. Flight phase, D. Landing position

Additionally, the non-signficiant, weak to moderate correlations may indicate the SLVH and horizontal jump tests assess different performance constructs. It is important to recall the context of these findings as the data in the current study is from patients during middle to later stages of rehabilitation after ACLR, all of whom had the goal of returning to sport.

In this cohort, the asymmetry of LSI on the SLVH was approximately $10 \%$ or more than each of the horizontal hop tests. This large asymmetry is relevant to clinicians as the lower LSI on the SLVH compared to the horizontal hop tests may indicate that the SLVH test identifies performance deficits that commonly used horizontal hop tests may not. The results are in agreement with those of Taylor et al. who found that participants after ACLR exhibited significant side-to-side differences during the SLVH with the involved limb hopping to a lower height. ${ }^{16}$ Biomechanical studies have found that participants after ACLR demonstrate a reduced angular impulse at the knee and greater inter-joint coordination asymmetry on the SLVH test. ${ }^{16,33}$ King et al. demonstrated similar findings with large effect size differences in internal knee valgus moment and posterior center of mass distance on a single leg drop jump task at nine months post ACLR. ${ }^{40}$ Performance deficits on the SLVH may correlate to these biomechanical deficits and may be clinically relevant for healthcare providers who use these tests in determining readiness for athletic activities or to guide rehabilitation.

Previous authors have shown that the SLVH is positively correlated with patient-reported IKDC scores, Tegner activity scale, ACL-RSI scale, isokinetic extensor muscle strength, carioca, and shuttle run tests. ${ }^{14,15,17,29}$ The relationship between SLVH and quadriceps strength may be of particular importance as better quadriceps function after ACLR is associated with improved patient reported outcome measures, gait quality, and return to sport rates, and reduced risk of re-injury. ${ }^{10,15,41-44}$ These additional measures were not directly measured in this study, however the previously documented findings serve to justify the use of the simple clinical test.

The weak correlations between the SLVH test and the horizontal hop tests indicate that the SLVH test likely provides a different assessment of the functional status of the knee. In this cohort, $77.78 \%$ of patients demonstrated LSI $\geqslant$ $90 \%$ on all horizontal hop tests at $7.33 \pm 2.05$ months after surgery. The pass rate exceeds the pass rate of $52.5 \%$ at 12 months after surgery reported by Logerstedt et al. from the Delaware-Oslo Cohort. ${ }^{45}$ This suggests the current cohort
Table 2. Sports played by subjects

\begin{tabular}{|c|c|}
\hline Sport Played & Number $(\mathbf{n}=18)$ \\
\hline Men's Lacrosse & 3 \\
\hline Women's Lacrosse & 2 \\
\hline Football & 3 \\
\hline Field Hockey & 2 \\
\hline Women's Soccer & 6 \\
\hline Softball & 2 \\
\hline
\end{tabular}

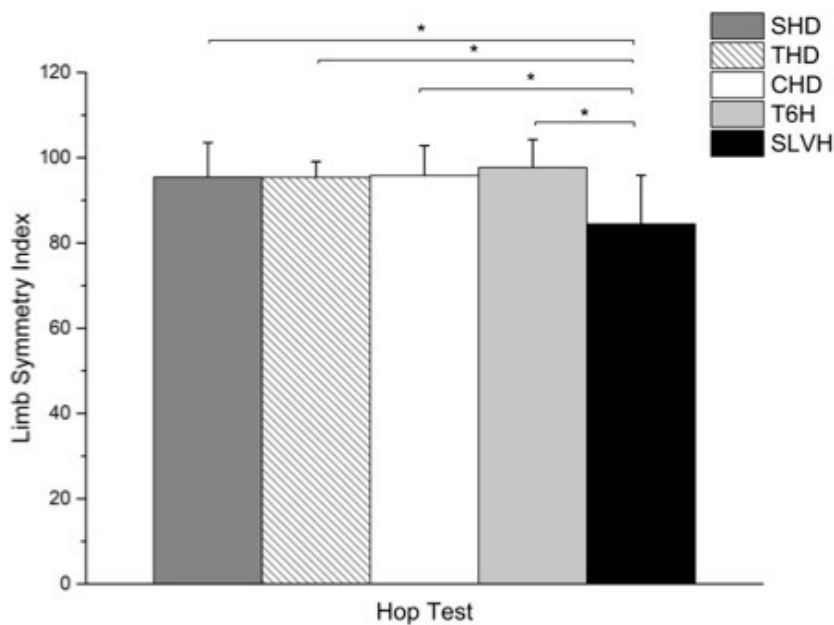

Figure 2. LSI results across the five hop tests, presented as $\%$, with $<100 \%$ indicating that the involved (surgical) limb performed worse than the non-surgical limb

LSI: Limb Symmetry Index, SHD: Single hop for distance, THD: Triple hop for distance, CHD: Crossover hop for distance, T6H: Timed 6-meter hop SLVH: Single leg vertical hop for height.

* = statistically significant difference $(\mathrm{p} \leq 0.05)$

was made up of high performers, however only $33.33 \%$ of patients demonstrated LSI $\geqslant 90 \%$ on the SLVH. This is clinically relevant as the horizontal hop testing data would suggest this group was made up of high performers, while the SLVH detected persistent knee function deficits.

Traditional horizontal hop testing alone after ACLR may not capture bilateral or absolute deficits. ${ }^{36,46}$ Similarly, normal hopping function is difficult to define as even healthy athletes may not be symmetrical. ${ }^{47}$ Patterson et 
A.

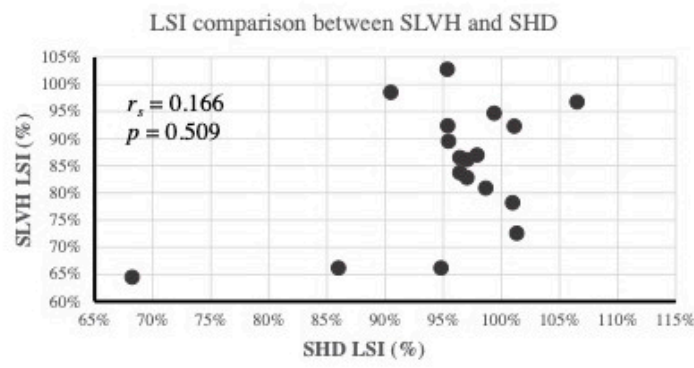

C.

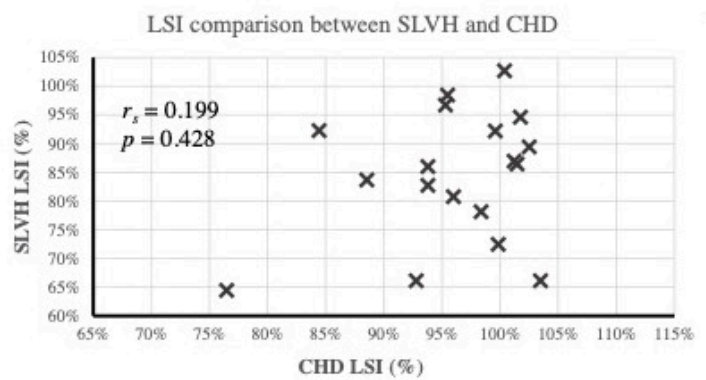

B.

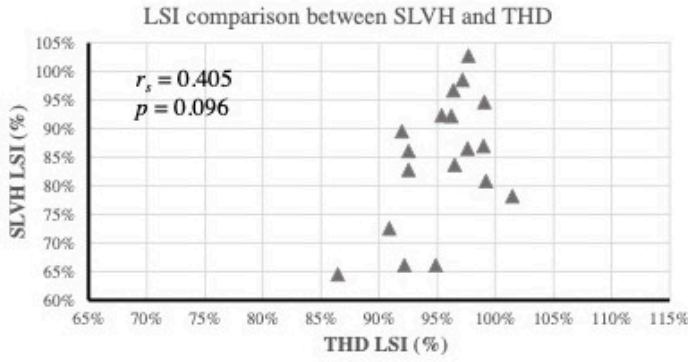

D.

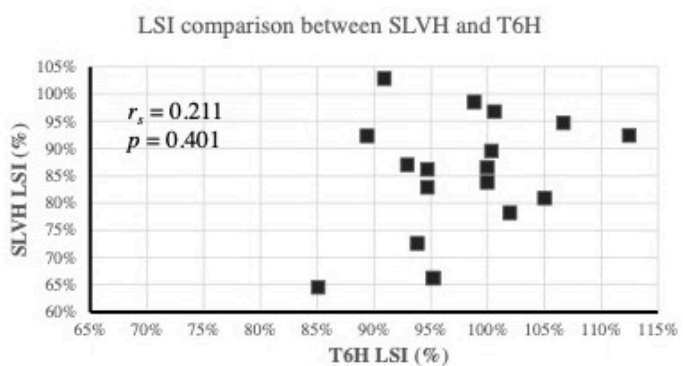

Figure 3. LSI for the SLVH compared to the four horizontal hop test, with SLVH (y-axis) compared to the four horizontal hop tests (A-D, $\mathrm{x}$-axis).

LSI: Limb Symmetry Index, SHD: Single hop for distance, THD: Triple hop for distance, CHD: Crossover hop for distance, T6H: Timed 6-meter hop, SLVH: Single leg vertical hop for height

al. identified performance deterioration of the uninvolved limb between one and five years after ACLR suggesting inter-limb comparisons may be flawed as the uninvolved limb may not be functioning optimally after surgery due to deconditioning. ${ }^{48}$ Acknowledging the importance of absolute values, Wellsandt et al. proposed testing the contralateral limb pre-operatively to establish a baseline value before surgery when using LSI as part of RTS decision making. ${ }^{30}$ It is important to acknowledge the limitations of hop testing.

Even if LSI calculated on horizontal hopping performance is to be used as part of the RTS decision, the strategy by which athletes hop must be considered. In their systematic review with meta-analysis of 624 patients after ACLR, Kotsifaki et al. found that athletes may demonstrate adequate distance on the SHD by adopting hip, knee, and ankle strategies suggesting horizontal hop tests alone may be misleading. 34

Recent studies observing the validity of RTS testing and outcomes have shown no significant relationship between passing hop tests and re-injury. ${ }^{19,31,32}$ Similarly, passing RTS batteries may not guarantee successful return to sport or be associated with optimal knee function. ${ }^{31}$ However, other authors have suggested that RTS testing is associated with reduced re-injury risk. ${ }^{10-12}$ Clinical testing for RTS remains controversial however a primary benefit testing is that it provides the ability to longitudinally track progress over time. Clinical tests such as SLVH and horizontal hop testing are cost-effective, simple to perform, and empower both the patient and healthcare team to objectively assess recovery and guide functional progression through the rehabilitation process. Additionally, more comprehensive testing procedures that include outcome measures such as diverse hopping tasks, strength, power, movement quality, and psychological status can provide valuable information and more broadly assess recovery and may add value. ${ }^{26,27,49,50} \mathrm{~A}$ holistic approach to RTS testing can help clinicians carefully assess and guide each patient through return to sport rather than be used as a simple pass or fail concept. ${ }^{37,51-53}$

While the data from this study adds to the discussion regarding hop testing, there are several limitations. This study was a retrospective cohort analysis, which could introduce selection bias. Careful consideration was given to the inclusion and exclusion criterion to minimize this risk. Similarly, in this cohort, only the included hop tests were uniformly performed and reported on. Other assessments of function, strength, power, and patient-reported outcome measures were used, but in an evolving manner that reflects clinical practice and were not identical among subjects or appropriate to report. Relationships between these additional measures and SLVH are purely speculative. All subjects were NCAA Division 1 collegiate athletes, played a variety of sports, and were operated on and provided rehabilitation by providers from a single institution; the results therefore cannot be generalized to all patients. Furthermore, the horizontal hop test pass rates at $7.33 \pm 2.05$ months after surgery exceeded previously reported pass rate at 12 months and likely do not reflect the performance of all patients after ACLR. Tests with high inter-rater reliability were used to minimize error. ${ }^{20}$ For example, jump mats are accurate, reliable, and cost efficient when compared to a 3-dimensional motion capture system and is correlated with force plate assessment of jump height. ${ }^{38,54-56}$ The $\mathrm{T} 6 \mathrm{H}$ test, which was timed with a standard timer may 
result in faster times compared to automatic timers and should be interpreted with caution. ${ }^{57}$ Additionally, it is important to consider other variables that could affect jump height such as jump type, strategy, and instructions. ${ }^{54,57-60}$ Therefore, instructions were to perform countermovement, single leg vertical hop as high as possible and hold the landing on the testing leg for two seconds and not excessively flex the hips while in the air to prevent artificially increasing flight time.

Future studies should assess the relationship between SLVH and other assessments and include longer tracking of outcomes related to autograft failures, contralateral ACL tears, and return to performance.

\section{CONCLUSION}

The results of this study indicate that SLVH elicits different LSI values after ACLR than horizontal hop tests. In this co- hort, the majority of patients who performed well on horizontal hop tests did not perform as well on the SLVH. Clinicians should strive to use the most valid and appropriate tests to assess outcomes after ACLR and should consider using SLVH as horizontal hop testing may not capture all deficits in performance.

\section{CONFLICTS OF INTEREST}

The authors have no financial disclosures to report.

Submitted: April 15, 2021 CST, Accepted: August 17, 2021 CST 


\section{REFERENCES}

1. Gornitzky AL, Lott A, Yellin JL, Fabricant PD, Lawrence JT, Ganley TJ. Sport-specific yearly risk and incidence of anterior cruciate ligament tears in high school athletes: A systematic review and metaanalysis. Am J Sports Med. 2016;44(10):2716-2723. 므 i:10.1177/0363546515617742

2. Herzog MM, Marshall SW, Lund JL, Pate V, Mack CD, Spang JT. Trends in incidence of ACL reconstruction and concomitant procedures among commercially insured individuals in the United States, 2002-2014. Sports Health. 2018;10(6):523-531. doi:10.1177/1941738118803616

3. Wright RW, Magnussen RA, Dunn WR, Spindler KP. Ipsilateral graft and contralateral ACL rupture at five years or more following ACL reconstruction: A systematic review. J Bone Jt Surg. 2011;93(12):1159-1165. doi:10.2106/jbjs.j.00898

4. Ardern CL, Taylor NF, Feller JA, Webster KE. Fiftyfive per cent return to competitive sport following anterior cruciate ligament reconstruction surgery: An updated systematic review and meta-analysis including aspects of physical functioning and contextual factors. Br J Sports Med.

2014;48(21):1543-1552. doi:10.1136/bjsports-2013-09 $\underline{3398}$

5. Meredith SJ, Rauer T, Chmielewski TL, et al. Return to sport after anterior cruciate ligament injury: Panther Symposium ACL injury return to sport consensus group. Orthop J Sports Med. 2020;8(6):2325967120930829. doi:10.1177/232596712 $\underline{0930829}$

6. Lai CCH, Ardern CL, Feller JA, Webster KE. Eightythree per cent of elite athletes return to preinjury sport after anterior cruciate ligament reconstruction: A systematic review with meta-analysis of return to sport rates, graft rupture rates and performance outcomes. Br J Sports Med. 2018;52(2):128-138. doi:1 0.1136/bjsports-2016-096836

7. Noyes FR, Barber SD, Mangine RE. Abnormal lower limb symmetry determined by function hop tests after anterior cruciate ligament rupture. Am J Sports Med. 1991;19(5):513-518. doi:10.1177/036354659101 $\underline{900518}$

8. Hopper DM, Goh SC, Wentworth LA, et al. Test-retest reliability of knee rating scales and functional hop tests one year following anterior cruciate ligament reconstruction. Phys Ther Sport. 2002;3(1):10-18. doi:10.1054/ptsp.2001.0094
9. Sueyoshi T, Nakahata A, Emoto G, Yuasa T. Singleleg hop test performance and isokinetic knee strength after anterior cruciate ligament reconstruction in athletes. Orthop J Sports Med. 2017;5(11):232596711773981. doi:10.1177/232596711 $\underline{7739811}$

10. Grindem H, Snyder-Mackler L, Moksnes H, Engebretsen L, Risberg MA. Simple decision rules can reduce reinjury risk by $84 \%$ after ACL reconstruction: The Delaware-Oslo ACL cohort study. Br J Sports Med. 2016;50(13):804-808. doi:10.1136/bjsports-2016-0960 $\underline{31}$

11. Kyritsis P, Bahr R, Landreau P, Miladi R, Witvrouw E. Likelihood of ACL graft rupture: Not meeting six clinical discharge criteria before return to sport is associated with a four times greater risk of rupture. $\mathrm{Br}$ J Sports Med. 2016;50(15):946-951. doi:10.1136/bjspor ts-2015-095908

12. Capin JJ, Snyder-Mackler L, Risberg MA, Grindem $\mathrm{H}$. Keep calm and carry on testing: A substantive reanalysis and critique of "what is the evidence for and validity of return-to-sport testing after anterior cruciate ligament reconstruction surgery? A systematic review and meta-analysis.' Br J Sports Med. 2019;53(23):1444-1446. doi:10.1136/bjsports-2019-10 $\underline{0906}$

13. Burgi CR, Peters S, Ardern CL, et al. Which criteria are used to clear patients to return to sport after primary ACL reconstruction? A scoping review. $\mathrm{Br} J$ Sports Med. 2019;53(18):1154-1161. doi:10.1136/bjsp orts-2018-099982

14. Lee DW, Yang SJ, Cho SI, Lee JH, Kim JG. Singleleg vertical jump test as a functional test after anterior cruciate ligament reconstruction. The Knee. 2018;25(6):1016-1026. doi:10.1016/j.knee.2018.07.01 4

15. Fischer F, Blank C, Dünnwald T, et al. Isokinetic extension strength is associated with single-leg vertical jump height. Orthop J Sports Med. 2017;5(11):232596711773676. doi:10.1177/232596711 $\underline{7736766}$

16. Taylor JB, Westbrook AE, Head PL, Glover KM, Paquette MR, Ford KR. The single-leg vertical hop provides unique asymmetry information in individuals after anterior cruciate ligament reconstruction. Clin Biomech. 2020;80:105107. doi:1 0.1016/j.clinbiomech.2020.105107 
17. Laudner K, Evans D, Wong R, et al. Relationship between isokinetic knee strength and jump characteristics following anterior cruciate ligament reconstruction. Int J Sports Phys Ther.

2015;10(3):272-280.

18. Kotsifaki A, Korakakis V, Graham-Smith P, Sideris V, Whiteley R. Vertical and horizontal hop performance: Contributions of the hip, knee, and ankle. Sports Health. 2021;13(2):128-135. doi:10.117 $\underline{7 / 1941738120976363}$

19. Losciale JM, Zdeb RM, Ledbetter L, Reiman MP, Sell TC. The association between passing return-tosport criteria and second anterior cruciate ligament injury risk: A systematic review with meta-analysis. J Orthop Sports Phys Ther. 2019;49(2):43-54. doi:10.251 9/jospt.2019.8190

20. Reid A, Birmingham TB, Stratford PW, Alcock GK, Giffin JR. Hop testing provides a reliable and valid outcome measure during rehabilitation after anterior cruciate ligament reconstruction. Phys Ther. 2007;87(3):337-349. doi:10.2522/ptj.20060143

21. Read PJ, Michael Auliffe S, Wilson MG, GrahamSmith P. Lower limb kinetic asymmetries in professional soccer players with and without anterior cruciate ligament reconstruction: Nine months is not enough time to restore "functional" symmetry or return to performance. Am J Sports Med. 2020;48(6):1365-1373. doi:10.1177/036354652091221 $\underline{8}$

22. Diermeier TA, Rothrauff BB, Engebretsen L, et al. Treatment after ACL injury: Panther Symposium ACL treatment consensus group. Br J Sports Med. 2020;55(1):14-22. doi:10.1136/bjsports-2020-102200

23. Nagelli CV, Hewett TE. Should return to sport be delayed until 2 years after anterior cruciate ligament reconstruction? Biological and functional considerations. Sports Med. 2017;47(2):221-232. doi:1 $\underline{0.1007 / \mathrm{s} 40279-016-0584-\mathrm{z}}$

24. Angelozzi M, Madama M, Corsica C, et al. Rate of force development as an adjunctive outcome measure for return-to-sport decisions after anterior cruciate ligament reconstruction. J Orthop Sports Phys Ther. 2012;42(9):772-780. doi:10.2519/jospt.2012.3780

25. King E, Franklyn-Miller A, Richter C, et al. Clinical and biomechanical outcomes of rehabilitation targeting intersegmental control in athletic groin pain: Prospective cohort of 205 patients. Br J Sports Med. 2018;52(16):1054-1062. doi:10.1136/bjsports-20 $\underline{16-097089}$
26. Webster KE, Feller JA, Lambros C. Development and preliminary validation of a scale to measure the psychological impact of returning to sport following anterior cruciate ligament reconstruction surgery. Phys Ther Sport. 2008;9(1):9-15. doi:10.1016/j.ptsp.20 $\underline{07.09 .003}$

27. Turpeinen JT, Freitas TT, Rubio-Arias JÁ, Jordan MJ, Aagaard P. Contractile rate of force development after ACL reconstruction - a comprehensive review and meta-analysis. Scand J Med Sci Sports. 2020;30(9):1572-1585. doi:10.1111/sms.13733

28. Orishimo KF, Kremenic IJ, Mullaney MJ, McHugh MP, Nicholas SJ. Adaptations in single-leg hop biomechanics following anterior cruciate ligament reconstruction. Knee Surg Sports Traumatol Arthrosc. 2010;18(11):1587-1593. doi:10.1007/s00167-010-118 $\underline{5-2}$

29. Nagai T, Schilaty ND, Laskowski ER, Hewett TE. Hop tests can result in higher limb symmetry index values than isokinetic strength and leg press tests in patients following ACL reconstruction. Knee Surg Sports Traumatol Arthrosc. 2020;28(3):816-822. doi:1 $\underline{0.1007 / \mathrm{s} 00167-019-05513-3}$

30. Wellsandt E, Failla MJ, Snyder-Mackler L. Limb symmetry indexes can overestimate knee cunction after anterior cruciate ligament injury. J Orthop Sports Phys Ther. 2017;47(5):334-338. doi:10.2519/jospt.201 $\underline{7.7285}$

31. Losciale JM, Bullock G, Cromwell C, Ledbetter L, Pietrosimone L, Sell TC. Hop testing lacks strong association with key outcome variables after primary anterior cruciate ligament reconstruction: A systematic review. Am J Sports Med. 2020;48(2):511-522. doi:10.1177/0363546519838794

32. Webster KE, Hewett TE. What is the evidence for and validity of return-to-sport testing after anterior cruciate ligament reconstruction surgery? A Systematic review and meta-analysis. Sports Med. 2019;49(6):917-929. doi:10.1007/s40279-019-01093-x

33. Blache Y, Pairot de Fontenay B, Argaud S, Monteil $\mathrm{K}$. Asymmetry of inter-joint coordination during single leg jump after anterior cruciate ligament reconstruction. Int J Sports Med. 2016;38(02):159-167. doi:10.1055/s-0042-109976

34. Kotsifaki A, Korakakis V, Whiteley R, Van Rossom S, Jonkers I. Measuring only hop distance during single leg hop testing is insufficient to detect deficits in knee function after ACL reconstruction: a systematic review and meta-analysis. Br J Sports Med. 2020;54(3):139-153. doi:10.1136/bjsports-2018-09991 $\underline{8}$ 
35. Dingenen B, Gokeler A. Optimization of the return-to-sport paradigm after anterior cruciate ligament reconstruction: A critical step back to move forward. Sports Med. 2017;47(8):1487-1500. doi:10.10 07/s40279-017-0674-6

36. Gokeler A, Welling W, Benjaminse A, Lemmink K, Seil R, Zaffagnini S. A critical analysis of limb symmetry indices of hop tests in athletes after anterior cruciate ligament reconstruction: A case control study. Orthop Traumatol Surg Res. 2017;103(6):947-951. doi:10.1016/j.otsr.2017.02.015

37. Gokeler A, Welling W, Zaffagnini S, Seil R, Padua D. Development of a test battery to enhance safe return to sports after anterior cruciate ligament reconstruction. Knee Surg Sports Traumatol Arthrosc. 2017;25(1):192-199. doi:10.1007/s00167-016-4246-3

38. Leard JS, Cirillo MA, Katsnelson E, et al. Validity of two alternative systems for measuring vertical jump height. J Strength Cond Res. 2007;21(4):1296-1299. doi:10.1519/r-21536.1

39. Schober P, Boer C, Schwarte LA. Correlation coefficients: Appropriate use and interpretation. Anesth Analg. 2018;126(5):1763-1768. doi:10.1213/an e.0000000000002864

40. King E, Richter C, Franklyn-Miller A, et al. Wholebody biomechanical differences between limbs exist 9 months after ACL reconstruction across jump/ landing tasks. Scand J Med Sci Sports. 2018;28(12):2567-2578. doi:10.1111/sms.13259

41. Lepley LK. Deficits in quadriceps strength and patient-oriented outcomes at return to activity after ACL reconstruction: A review of the current literature. Sports Health. 2015;7(3):231-238. doi:10.11 77/1941738115578112

42. Snyder-Mackler L, Delitto A, Bailey SL, Stralka SW. Strength of the quadriceps femoris muscle and functional recovery after reconstruction of the anterior cruciate ligament. A prospective, randomized clinical trial of electrical stimulation. $J$ Bone Joint Surg Am. 1995;77(8):1166-1173. doi:10.210 6/00004623-199508000-00004

43. Zwolski C, Schmitt LC, Quatman-Yates C, Thomas S, Hewett TE, Paterno MV. The influence of quadriceps strength asymmetry on patient-reported function at time of return to sport after anterior cruciate ligament reconstruction. Am J Sports Med. 2015;43(9):2242-2249. doi:10.1177/036354651559125 $\underline{8}$

44. Chaput M, Palimenio M, Farmer B, et al. Quadriceps strength influences patient function more than single leg forward hop during late-stage ACL rehabilitation. Int J Sports Phys Ther. 2021;16(1):145-155. doi:10.26603/001c.18709
45. Logerstedt D, Di Stasi S, Grindem H, et al. Selfreported knee function can identify athletes who fail return-to-activity criteria up to 1 year after anterior cruciate ligament reconstruction: a delaware-oslo ACL cohort study. J Orthop Sports Phys Ther. 2014;44(12):914-923. doi:10.2519/jospt.2014.4852

46. King E, Richter C, Daniels KAJ, et al. Can biomechanical testing after anterior cruciate ligament reconstruction identify athletes at risk for subsequent ACL injury to the Contralateral Uninjured Limb? Am J Sports Med. 2021;49(3):609-619. doi:10.11 77/0363546520985283

47. Greenberg EM, Dyke J, Leung A, Karl M, Lawrence JT, Ganley T. Uninjured youth athlete performance on single-leg hop testing: How many can achieve recommended return-to-sport criterion? Sports Health. 2020;12(6):552-558. doi:10.1177/1941738120 911662

48. Patterson BE, Crossley KM, Perraton LG, et al. Limb symmetry index on a functional test battery improves between one and five years after anterior cruciate ligament reconstruction, primarily due to worsening contralateral limb function. Phys Ther Sport. 2020;44:67-74. doi:10.1016/j.ptsp.2020.04.031

49. Angelozzi M, Madama M, Corsica C, et al. Rate of force development as an adjunctive outcome measure for return-to-sport decisions after anterior cruciate ligament reconstruction. J Orthop Sports Phys Ther. 2012;42(9):772-780. doi:10.2519/jospt.2012.3780

50. Jordan MJ, Aagaard P, Herzog W. Lower limb asymmetry in mechanical muscle function: A comparison between ski racers with and without ACL reconstruction: Bilateral asymmetry in ACL-R ski racers. Scand J Med Sci Sports. 2015;25(3):e301-e309. doi:10.1111/sms.12314

51. Buckthorpe M, Della Villa F, Della Villa S, Roi GS. On-field rehabilitation part 1: 4 pillars of high-1uality on-field rehabilitation are restoring movement quality, physical conditioning, restoring sportspecific skills, and progressively developing chronic training load. J Orthop Sports Phys Ther. 2019;49(8):565-569. doi:10.2519/jospt.2019.8954

52. Buckthorpe M, Della Villa F, Della Villa S, Roi GS. On-field rehabilitation part 2: A 5-stage program for the soccer player focused on linear movements, multidirectional movements, soccer-specific skills, soccer-specific movements, and modified practice. $J$ Orthop Sports Phys Ther. 2019;49(8):570-575. doi:10.2 519/jospt.2019.8952

53. Dingenen B, Gokeler A. Optimization of the return-to-sport paradigm after anterior cruciate ligament reconstruction: A critical step back to move forward. Sports Med. 2017;47(8):1487-1500. doi:10.10 07/s40279-017-0674-6 
54. Rogan S, Radlinger L, Imhasly C, Kneubuehler A, Hilfiker R. Validity study of a jump mat compared to the reference standard force plate. Asian J Sports Med. $2015 ; 6(4)$. doi:10.5812/asjsm.25561

55. Pueo B, Lipinska P, Jiménez-Olmedo JM, Zmijewski P, Hopkins WG. Accuracy of jump-mat systems for measuring jump height. Int J Sports Physiol Perform. 2017;12(7):959-963. doi:10.1123/ijsp p.2016-0511

56. Whitmer TD, Fry AC, Forsythe CM, et al. Accuracy of a vertical jump contact mat for determining jump height and flight time. J Strength Cond Res. 2015;29(4):877-881. doi:10.1519/jsc.00000000000005 $\underline{42}$

57. Acero RM, Sánchez JA, Fernández-del-Olmo M. Tests of vertical jump: Countermovement jump with arm swing and reaction jump with arm swing. Strength Cond J. 2012;34(6):87-93. doi:10.1519/ssc.0b 013e318276c353
58. Ferreira LC, Schilling BK, Weiss LW, Fry AC, Chiu LZF. Reach height and jump displacement: Implications for standardization of reach determination. J Strength Cond Res.

2010;24(6):1596-1601. doi:10.1519/jsc.0b013e3181d5 $\underline{4 a 25}$

59. Menzel H-J, Chagas MH, Szmuchrowski LA, Araujo SR, Campos CE, Giannetti MR. Usefulness of the jump-and-reach test in assessment of vertical jump performance. Percept Mot Skills. 2010;110(1):150-159. doi:10.2466/pms.110.1.150-158

60. Kenny IC, Cairealláin AÓ, Comyns TM. Validation of an electronic jump mat to assess stretchshortening cycle function. J Strength Cond Res. 2012;26(6):1601-1608. doi:10.1519/jsc.0b013e318234 ebb8 